\title{
Construction of Evaluation Indexes for the Integrated Development of Leisure Agriculture Management: The Application of Delphi Technology
}

\author{
Chun-Nan Lin1, Ta-An Hung2, Hsiao-Hui Li ${ }^{3 *}$ \\ ${ }^{1}$ Department of Agribusiness Management, National Ping-Tung University of Science and Technology, Taiwan \\ ${ }^{2}$ Bachelor Program of Law, TOKO University, Taiwan \\ ${ }^{3}$ Department of Information Management, Tainan University of Technology, Taiwan \\ Email: ^xiasohui@gmail.com
}

How to cite this paper: Lin, C.-N., Hung, T.-A. and Li, H.-H. (2020) Construction of Evaluation Indexes for the Integrated Development of Leisure Agriculture Management: The Application of Delphi Technology. Open Access Library Journal, 7: e6264. https://doi.org/10.4236/oalib.1106264

Received: March 24, 2020

Accepted: April 21, 2020

Published: April 24, 2020

Copyright (๑) 2020 by author(s) and Open Access Library Inc.

This work is licensed under the Creative Commons Attribution International License (CC BY 4.0).

http://creativecommons.org/licenses/by/4.0/

\begin{abstract}
Leisure agriculture is a new industry that applies agricultural resources to leisure and recreational activities to meet the needs of tourists, increase farmers' income, and then increase the value of agriculture. The purpose of this research is to develop structured evaluation indicators to analyze the comprehensive development of leisure agricultural management, and becomes a business model that can be quantitatively replicated. The study after screening by the Delphi Method, the five evaluation aspects of "corporate organization operation", "leisure agricultural resources", "maintenance of the operating environment", "maintenance of surrounding facilities" and "operating performance" and 21 evaluation criteria are established. The research results show that leisure agriculture enterprises can be used as the evaluation aspect and evaluation criteria for leisure agricultural operations. Besides, according to the technical analysis of Delphi method, leisure agricultural operations should pay attention to the smoothness of internal operations and key processes of the enterprise organization, and strive to integrate resources inside and outside the enterprise. Only with the concept of integrated development can we create sustainable management of leisure business.
\end{abstract}

\section{Subject Areas \\ Business \& Economics}

\section{Keywords}

Leisure Agriculture Management, Integrated Development, Evaluation 
Indicators, Delphi Technology

\section{Introduction}

Taiwan's "leisure agriculture" has established this term as early as 1989. The precise leisure agriculture is: "Using rural equipment, rural space, agricultural production sites, products, agricultural business activities, ecology, agricultural, natural environment, and rural areas". Human resources have been planned and designed to give play to agricultural and rural recreational functions. Enhance Chinese people's experience in agriculture and rural areas, improve recreational quality and increase farmers' income, and promote rural development [1] and agriculture in Taiwan Business offers another way of development.

Leisure agriculture is a new industry that applies agricultural resources to leisure and recreation activities to meet the needs of tourists, increase farmers' income, and then increase the value of agriculture. It is a creative industry that responds to the needs of the times [2]. In terms of management, the central axis is the localization of agriculture, taking into account the compatibility of agricultural production with the natural ecological environment, covering the "three agriculture, three lives, and agriculture" of agricultural production, peasant life, and rural ecology industry, secondary processing industry, and tertiary service industry.

There are complexity and diversity in the use of resources in the management of leisure agriculture. It is necessary to use the concept of integration for the development of management, and the concept of management cannot be described in simple words. Evaluation indicators can analyze the integrated development of leisure agricultural operations and become a business model that can be quantitatively copied.

\section{Literature Review}

\subsection{Management Aspects of Leisure Agriculture}

The influence of leisure managers on organizational performance is particularly important. Due to the proper use of resources, the competitive advantages of leisure agricultural operations will be enhanced, and the organization's operating capacity will be improved. The operating capacity refers to the organization's production, marketing, human resources, research and development, the overall operation of finance. The description of the leisure agriculture management structure is roughly based on the resource base [1], key processes [3], and business performance [4] as the main descriptions. It can be seen that the improvement of leisure agriculture business performance, the source result of the impact of leisure agricultural resource grasp, and the organizational operation process. The management facet is based on the resources at the time of the operation. It is considered from the externally available resources and the conditions of its 
ownership, including the four main items of the business entity, land attributes, resource characteristics, and professional functions [5].

\subsection{Integrated Development Mode of Operation}

"Integration" is often regarded as a positive way to eliminate conflicts [3]. It can be described as the concept of "adjustment and cooperation" between organizations or departments, which form an entirety in an orderly manner. Subjectivity and cultural differences remain [6]. To emphasize the interdependence of constituents, it is often integrated into the concept description of "system" [7] to achieve a certain degree of unity and harmony to maintain the survival of the organization [8]. As competition between industries becomes more complex, "integration" is increasingly becoming the core of management work [3]. Through resource integration, due to the lack of their resources, different organizations, networks, and groups must make up for their deficiencies through exchanges and integration [9]; the so-called integrated development model is the various resources and information inside and outside the organization., And through the integration of various goals and consistent results distribution to achieve the ultimate goal [10], to obtain different types of resources through resource integration, reduce time and operating costs, and improve operating performance [11].

\subsection{Evaluation Indicators for Leisure Agriculture}

Aiming at the criteria for the evaluation of leisure agriculture operations, [1] explores the aspects that should be emphasized in the development of leisure agriculture, with "organizational operation" having the most significant impact, followed by "resource sharing" and finally "environment management". Reviewing the literature of previous scholars, this study is summarized that the evaluation indicators for the integrated development of leisure agriculture. The evaluation indicators include organizational operation, leisure agricultural resources, environmental maintenance management, public facilities maintenance management, operational performance, competitive advantage, customer value proposition, agricultural land resource restrictions, and experience quality [1] [4] [5] [8] [10]. This article reduced it to five evaluation aspects, including enterprise organization and operation, leisure agricultural resources, maintenance of the operating environment, maintenance of surrounding facilities, and operating performance.

\section{Research Methods}

Index construction methods can be roughly divided into two types: qualitative methods and quantitative methods. Qualitative methods such as literature analysis, expert discussion, interview methods, focus group methods, and brainstorming methods, etc. And quantitative methods include questionnaire survey methods, such as factor analysis, Delphi method, and the analytic hierarchy 
process (AHP) analysis method [12]. In the early stage of construction, it is appropriate to use the literature method and the Delphi method to gather consensus. Therefore, this article attempts to use the literature method and Delphi technology as the research method to conduct this research.

\subsection{Delphi Method}

This paper uses the characteristics of the Delphi method to provide collective consensus for this research, propose contributions, and then achieve the purpose. The Delphi method is a method of providing information on unknown things through group wisdom. However, according to each expert's definition of the Delphi method, the Delphi method adopts anonymity, the characteristics of repeatedly collecting data to make the opinions of experts more consistent, the feedback of repeated loop questionnaires as a communication method, and the experts' answers to their own experience. Annotate, organize the recovered data, and provide statistical data in the prepared questionnaire for reference by experts [13].

Regarding the sample number of experts and scholars in the Delphi method, [13] believed that the number of experts and scholars participating in the study was better than five. Therefore, this study will select 5 experts and scholars from the industry, government, and academic circles for interviews. As for the Delphi Expert Questionnaire, this article assigns the importance of each index factor to "very unimportant", "unimportant", “normal", “important”, and "very important", with weights 1, 2, respectively. 3, 4, 5 represent their importance, and finally, integrate the importance of all interview experts on the attributes of individual.

\subsection{AHP Method}

The AHP method was abbreviated in the 1970s by the American operations researcher T.L. Saaty [14]. It is a systematic, hierarchical analysis method that combines qualitative and quantitative analysis. Because of its practicability and effectiveness in dealing with complex decision-making problems, it has quickly gained worldwide attention [15]. Its applications have spread across areas such as economic planning and management, energy policy and distribution, behavioral science, military command, transportation, agriculture, education, talent, healthcare, and the environment [14] [15] [16] [17]. There are many advantages to using AHP method, the most important of which is simplicity and clarity. AHP method is not only suitable for situations where there are uncertainty and subjective information, but also allows the logical use of experience, insight and intuition [17]. Perhaps the greatest advantage of the AHP method is the level itself, which enables buyers to seriously consider and measure the relative importance of indicators.

\subsection{Research Framework}

This article synthesizes relevant literature indicators to construct the evaluation 
indicators of leisure agricultural operations, which are five evaluation aspects, namely, "organizational operation of enterprises", "recreational agricultural resources", "maintenance of operating environment", "maintenance of surrounding facilities", and "operating performance". And its 21 sub-projects, each facet and the criteria of the sub-projects are described in Table 1: criteria to obtain the most appropriate answer.

\section{Empirical Analysis}

\subsection{Basic Data Analysis}

The research objects are experts, scholars, and scholars in the field of leisure agriculture. A total of 5 questionnaires were distributed, and 5 questionnaires were recovered. The questionnaire recovery rate was $100 \%$. The average working experience of experts was 23.2 years.

According to the information collected by the Delphi survey, the selection index is selected. The selection criteria for this study were selected using the default value of Power Choice 2.5 that mean $>3$ and coefficient of variation $\leq 0.5$.

Table 1. Aspects and criteria for evaluating the integrated development of leisure agricultural operation.

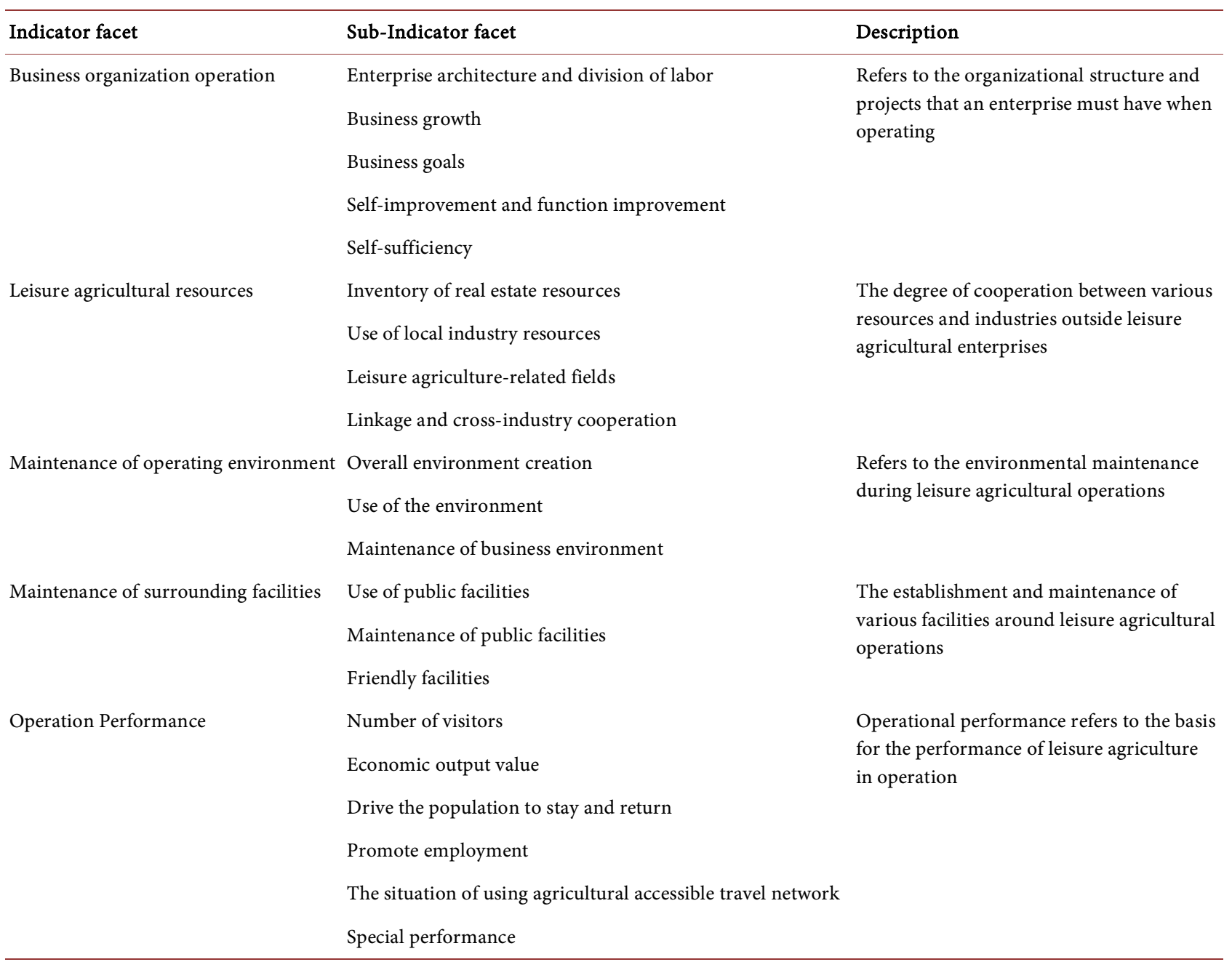


Coefficient of Variation $=$ Standard deviation/Average. The average and coefficient of variation analysis results are shown in Table 2 below.

\subsection{Results Analysis}

Among the five significant aspects of the integrated development assessment indicators for leisure agriculture management, the most critical aspects of the aggregated results are "corporate operation" (5), "leisure agricultural resources" (5), and "maintenance of the operating environment" (4.8), "Maintenance of

Table 2. Summary of the selection results of the factors of the Delphi method.

\begin{tabular}{|c|c|c|c|c|c|}
\hline Facet & Evaluation Criteria Name & Mean & $\begin{array}{l}\text { Coefficient of } \\
\text { Variation }\end{array}$ & $\begin{array}{l}\text { Selection } \\
\text { Result }\end{array}$ & Ranking \\
\hline \multirow[t]{5}{*}{ Business organization operation } & Enterprise architecture and division of labor & 5.0 & 0.0000 & $\mathrm{O}$ & 1 \\
\hline & Business growth & 3.6 & 0.2833 & $\mathrm{O}$ & 18 \\
\hline & Business goals & 4.6 & 0.1065 & $\mathrm{O}$ & 6 \\
\hline & Self-improvement and function improvement & 4.6 & 0.1065 & $\mathrm{O}$ & 6 \\
\hline & Self-sufficiency & 4.4 & 0.1113 & $\mathrm{O}$ & 12 \\
\hline \multirow[t]{3}{*}{ Leisure agricultural resources } & Inventory of real estate resources & 4.8 & 0.0833 & $\mathrm{O}$ & 3 \\
\hline & Use of local industry resources & 4.8 & 0.0833 & $\mathrm{O}$ & 3 \\
\hline & Linkage and cross-industry cooperation & 4.6 & 0.1065 & $\mathrm{O}$ & 6 \\
\hline \multirow{3}{*}{$\begin{array}{l}\text { Maintenance of operating } \\
\text { environment }\end{array}$} & Overall environment creation & 5.0 & 0.0000 & $\mathrm{O}$ & 1 \\
\hline & Use of the environment & 4.4 & 0.1113 & $\mathrm{O}$ & 12 \\
\hline & Maintenance of business environment & 4.6 & 0.1065 & $\mathrm{O}$ & 6 \\
\hline \multirow[t]{3}{*}{ Maintenance of surrounding facilities } & Use of public facilities & 4.4 & 0.1113 & $\mathrm{O}$ & 12 \\
\hline & Maintenance of public facilities & 4.4 & 0.1113 & $\mathrm{O}$ & 12 \\
\hline & Friendly facilities & 4.6 & 0.1065 & $\mathrm{O}$ & 6 \\
\hline \multirow[t]{5}{*}{ Operation Performance } & Number of visitors & 3.4 & 0.1441 & $\mathrm{O}$ & 20 \\
\hline & Economic output value & 4.2 & 0.1782 & $\mathrm{O}$ & 17 \\
\hline & Promote employment & 4.8 & 0.0833 & $\mathrm{O}$ & 3 \\
\hline & $\begin{array}{c}\text { The situation of using agricultural accessible } \\
\text { travel network }\end{array}$ & 3.6 & 0.2222 & $\mathrm{O}$ & 18 \\
\hline & Special performance & 3.2 & 0.1250 & $\mathrm{O}$ & 21 \\
\hline \multirow[t]{5}{*}{ Overall assessment } & Business organization operation & 5.0 & 0.0000 & $\mathrm{O}$ & 1 \\
\hline & Leisure agricultural resources & 5.0 & 0.0000 & $\mathrm{O}$ & 1 \\
\hline & Maintenance of operating environment & 4.8 & 0.0833 & $\mathrm{O}$ & 3 \\
\hline & Maintenance of surrounding facilities & 4.6 & 0.1065 & $\mathrm{O}$ & 4 \\
\hline & Operational performance & 4.2 & 0.1782 & $\mathrm{O}$ & 5 \\
\hline
\end{tabular}

Remark: " $\mathrm{O}$ " means that the evaluation result of this indicator is qualified. 
surrounding facilities" (4.6), "Operating performance" (4.2). It shows that "enterprise organization operation" and "leisure agricultural resources" are the most critical evaluation aspects.

Among the 21 factors for the evaluation index for the integrated development of leisure agricultural areas, the top five ranking evaluation criteria that experts and scholars value most are "enterprise structure and implementation of division of labor" (5) and "environmental maintenance Overall Environment Construction" (5), followed by "Inventory of Local Industry Resources" (4.8), "Use of Local Industry Resources" (4.8), and "Promote Employment” (4.8).

As shown in Table 2 above, in the "corporate organization operation" aspect, "enterprise structure and division of labor" (5) is the first place. In the "leisure agricultural resources" aspect, the "local industrial resource inventory" and "The use of resources in the real estate industry" (4.8) are tied in the first place. In the "operation environment maintenance" aspect, "the overall environment creation" (5) is the first place. In the "operation surrounding facilities maintenance" aspect, the "friendly facilities" "Setting" (4.6) is the most valued. In the "operational performance" aspect, "promoting employment" (4.8) is the most valued by experts and scholars.

\section{Conclusions and Suggestions}

\subsection{Conclusions}

After screening by the Delphi method, the five significant evaluation facets and 21 evaluation criteria have passed the test. Therefore, all evaluation facets and evaluation criteria are retained. The hierarchy structure diagram is unchanged. The conclusion analysis is as follows:

The integrated development measurement aspects of leisure agriculture management are first and foremost "enterprise organization operation" and "agricultural recreation resources". According to the analysis of the aspects of the Delphi technology, enterprise organization operations and leisure agricultural resources should pay attention to the internal operation and the integrity and fluency of critical processes, and attention to the resource base of leisure agriculture and the efficiency of resource use.

The organization and operation of leisure and agricultural enterprises should pay attention to the implementation of corporate structure and division of labor. In the maintenance of the operating environment, attention should be paid to the overall environmental creation. This has a great relationship with the establishment of the competitive advantages of corporate operations.

\subsection{Suggestions}

The organizational structure of leisure agricultural operation is the essential requirement for business operation. Enterprises should establish a sound organizational structure to implement the division of labor and the implementation of critical processes to integrate the resources of leisure business, the operating en- 
vironment, and the overall development of the enterprise. The integrated development measurement model is the most significant competitive advantage of the company.

Adhering to the resource base, leisure agriculture must strive to integrate resources inside and outside the enterprise. Only with the concept of integrated development can sustainable development of leisure business be created.

\section{Conflicts of Interest}

The authors declare no conflicts of interest regarding the publication of this paper.

\section{References}

[1] Liu, Y.L., Ho, L.M. and Liu, F. (2018) The Brand Management Evaluation Indicators Model of Agri-Tourism Farms: A Core Competence Perspective. Open Access Library Journal, 5, 1-9. https://doi.org/10.4236/oalib.1104827

[2] Bryant, C.R. and Chahine, G. (2016) Action Research and Reducing the Vulnerability of Peri-Urban Agriculture: A Case Study from the Montreal Region. Geographical Research, 54, 165-175. https://doi.org/10.1111/1745-5871.12119

[3] Winslow, M. (2020) Cultivating Leisure: Tourism, Progressive Agriculture, and Technologies of Landscape at Pinehurst, North Carolina, 1895-1935. Agricultural History, 94, 61-83. https://doi.org/10.3098/ah.2020.094.1.061

[4] Liu, F., Chien, I.L., Lan, M.Y. and Chien, Z.M. (2012) Development the Theme Park Brand Equity Model of Taiwan. International Journal of Psychology, 47, 174.

[5] Rzekęć, A., Vial, C. and Bigot, G. (2020) Green Assets of Equines in the European Context of the Ecological Transition of Agriculture. Animals, 10, 106.

https://doi.org/10.3390/ani10010106

[6] Liu, F. and Lee, M.J. (2012) Understanding the Island Tourism Image Formation in Taiwan: Via Fuzzy Preference Relations. International Journal of Psychology, 47, 174.

[7] Pu, S. and Wanf, F. (2014) Study on the Policies, Science and Technology Support to Impel the Development of Recreational Agriculture in Hainan. Asian Agricultural Research, 6, 31-35.

[8] Liu, F., Chou, M.Y., Liu, Y.L. and Chen, H.Z. (2013) The Role of Medical Word-of-Mouth on Sport Therapists: A Patient Psychological Perspectives. Open Journal of Medical Psychology, 2, 7-10. https://doi.org/10.4236/ojmp.2013.24B002

[9] Chen, Y., Liu, F., Ho, L.M. and Lin, T.M.Y. (2012) Development of Word-of-Mouth Elasticity Measures for Tourism Product Categories. Psychology, 3, 722-728. https://doi.org/10.4236/psych.2012.39109

[10] Wen, S.Y., Ouyang, C. and Liu, F. (2019) Effect of a Prospective Payment System on Agriculture Health Villages. ICIC Express Letters, Part B: Applications An International Journal of Research and Surveys, 10, 275-281.

[11] Chen, Y., Liu, F., Fang, C.H. and Lin, T.M.Y. (2013) Understanding the Effectiveness of Word-of Mouth: An Elasticity Perspective. Journal of Research in Interactive Marketing, 7, 57-77. https://doi.org/10.1108/17505931311316743

[12] Woodcock, T., Adeleke, Y., Goeschel, C., Pronovost, P. and Dixon-Woods, M. 
(2020) A Modified Delphi Study to Identify the Features of High Quality Measurement Plans for Healthcare Improvement Projects. BMC Medical Research Methodology, 20, 1-9. https://doi.org/10.1186/s12874-019-0886-6

[13] Xu, A., Zare, H., Dai, X., Xiang, Y. and Gaskin, D.J. (2019) Defining Hospital Community Benefit Activities Using Delphi Technique: A Comparison between China and the United States. PLoS ONE, 14, 1-15.

https://doi.org/10.1371/journal.pone.0225243

[14] Chia, E.L., Hubert, D., Enongene, K. and Tegegne, Y.T. (2020) An AHP Assessment of Barriers in Adopting Sustainable Forest Management Practices in The Context of Carbon Emission Reductions in Cameroon. Journal of Sustainable Forestry, 39, 379-391. https://doi.org/10.1080/10549811.2019.1673180

[15] Nielsen, A.M. and Fei, S.L. (2015) Assessing the Flexibility of the Analytic Hierarchy Process for Prioritization of Invasive Plant Management. NeoBiota, 27, 25-36. https://doi.org/10.3897/neobiota.27.4919

[16] An, Z. and Song, L. (2018) Research on the Role of AHP-Entropy Method in the Identification and Evaluation of China Tariff Source Risk. Journal of Intelligent \& Fuzzy Systems, 34, 1053-1060. https://doi.org/10.3233/JIFS-169399

[17] Zhou, S. and Yang, P. (2020) Risk Management in Distributed Wind Energy Implementing Analytic Hierarchy Process. Renewable Energy: An International Journal, 150, 616-623. https://doi.org/10.1016/j.renene.2019.12.125 